\title{
Novas espécies e notas sobre Euglossinae do Brasil e Venezuela (Hymenoptera, Apidae) ${ }^{1}$
}

\begin{abstract}
New species and notes on Euglossinae from Brasil and Venezuela. Eumorpha danielis (Schrottky, 1907) and Centris nigrita var. raymondi Schrottky, 1907, are trasferred to Euplusia Moure, 1943 and validated as Euplusia danielis and Euplusia raymondi comb.n.. Specimens from Santa Isabel do Morro, Ilha do Bananal, Tocantins, and from Santarém and Cachimbo, Pará, are described as Euplusia danielis fuscatra subsp.n., Euplusia fragocara Kimsey, 1977, was discovered in Ouro Preto d'Oeste, Rondônia; its female shows bluish colors as E. caerulaescens (Lepeletier, 1841 ), and $E$. violacea (Blanchard, 1840). The true meaning of $E$. smaragdina (Perty, 1833 ) as different from $E$. surinamensis (Linnaeus, 1758) is restored according to the study of the type specimen in Munich, Germany. E. xantha Kimsey, 1977 is a new synonym of $E$. vidua Moure, 1976. The following species from Brasil are described as new: Euplusia faceta from Mucujé, Bahia, Euplusia nordestina from Santa Luzia, Paraiba, and Euplusia velutina from Mérida, Northwestern Venezuela.

KEY WORDS. Euglossinae, systematics, Neotropical
\end{abstract}

Jesus S. Moure ${ }^{2}$

Há vários anos venho acumulando dados sobre Euglossinae e dou-os a conhecer neste trabalho.

\section{Euplusia danielis (Schrottky, 1907) stat.n., comb.n.}

Eumorpha combinata var. danielis Schrottky, 1907: 56.

Holótipo no Museu de Zoologia da Universidade de São Paulo, [n 102.887]; Paraguay Schrottky leg., etiqueta de Lüderwaldt e em etiqueta impressa de Schrottky, com a data de 1912: Eufriesea combinata (Mocs.) danielis Schrottky.

Comparei fêmeas de E. auriceps (Friese, 1899) com o tipo de $E$. danielis e acho que se trata de espécies muito próximas porém separáveis. Schrottky considerou E. auriceps como Centris violascens (Mocsary, 1898) concordando assim com a posição de KIMSEY (1982).

Macho de E. danielis de tamanho médio. Comprimento aproximado 16,5 $\mathrm{mm}$, da asa anterior $15,0 \mathrm{~mm}$; largura da cabeça $6,25 \mathrm{~mm}$, do T2 7,92 $\mathrm{mm}$.

Face com o clípeo verde, paroculares inferiores verde-douradas, embaixo um pouco para o azul-aço, para cima e meio da supraclipeal de um verde claro, com reflexos cúpreos na carena supralveolar; azul escuro na maior parte da área frontal passando a cúpreo inferiormente; labro escuro no disco e verde-azul aos lados; mandíbulas, na base, azuis. No vértice, genas, tórax e abdômen de um violáceo escuro, quase preto; manchas escutais verdes, os dois terços basais do T2 verde

1) Contribuição número 1128 do Departamento de Zoologia, Universidade Federal do Paraná.

2) Departamento de Zoologia, Universidade Federal do Paraná. Caixa Postal 19020, 81531-990 Curitiba, Paraná, Brasil. Bolsista do CNPq. 
garrafa escuro; tíbias posteriores com a face externa preta. Tégulas verdes na frente, pretas atrás, azuis no bordo externo; asas escuras, venação e estigma pretos.

Pilosidade predominante preta, amarela no clípeo e paroculares, com algumas cerdas no vértice; de um castanho escuro sobre as manchas escutais; branca na face externa dos basitarsos do segundo par; cerdinhas esparsas amarelentas na face externa das tíbias posteriores diminuindo em direção à fenda, adensando-se para cima e para trás; acima da fenda todas pretas sem formar estria. No abdome preta, porém com cerdas amarelas longas (até $800 \mu$ ) misturadas às pretas mais curtas nos três últimos tergos.

Pontuação densíssima na área frontal, em baixo de dois tamanhos até uma linha transversal em grande parte lisa, na largura máxima pouco abaixo do início das carenas adocelares (junto ao ocelo médio); abaixo dessa linha transversal densa e de dois tamanhos (60 e $30 \mu$ ), nula aos lados do sulco frontal; a supraclipeal densamente pontuada nos declives para os alvéolos, deixando larga estria lisa (com retículo muito superficial) entre o sulco frontal e o clípeo. Clípeo com pontução esparsa entre as carenas laterais, os intervalos micro-reticulados, para os lados e para baixo mais densa e mais forte com estreito bordo apical sem pontos; nas paroculares inferiores densa e forte, nas superiores mais esparsa e mais fina deixando uma área lisa aos lados dos alvéolos quase igualando seu diâmetro; nas genas bastante densa e de tamanho uniforme. No disco do labro muito esparsa e de vários tamanhos, nos lados fina e muito esparsa com micropontos intercalados, no terço distal entre as carenas quase sem pontos. No disco posterior do mesoscuto bastante densa e a diferença entre os pontos maiores e menores cerca de 40 e $20 \mu$; no escutelo muito densa e bastante uniforme. Nos tergos fina e densa, os intervalos como os pontos, muito uniforme na distribuição, mesmo na metade basal de T2.

Cabeça um pouco mais larga que longa (625:450); olhos duas vezes mais longos que largos, pouco mais que o dobro da largura das genas (440:220:95); área malar linear (10); órbitas mais separadas em baixo que em cima, a distância máxima menor que o comprimento do olho (248:330:290). Clípeo 1,27 vezes mais largo que longo, seu comprimento 1,37 vezes sua distância ao ocelo médio (280:220:160); as carenas laterais subparalelas, fracamente unidas em arco em cima com alguns pontos grossos, a carena média muito obsoleta um pouco elevada no meio, micro-reticulada e sem pontos; supraclipeal elevada em estria larga ao longo do meio, superficialmente micro-reticulada, sem pontos; carenas supralveolares e adocelares bem marcadas e lisas na cresta, as adocelares ligadas em ogiva paraboloide por trás do ocelo médio e seguidas para baixo em aresta fraca em forma de cálice; distância interalveolar quase duas vezes a alveolorbital e esta menor que o diâmetro do alvéolo (100:60:D45); distância interocelar duas vezes o ocelo médio, 1,6 vezes a ocelorbital (80:50:D40). Labro um pouco mais largo que longo (140:110), com o bordo inferior ligeiramente sinuado, tri-carenado, a carena média nos dois quintos basais, as laterais agudas, convergentes para baixo, todas curtamente entumescidas na base, de perfil saliente. Mandíbulas bidentadas, com o bordo externo em arco levemente sinuado; complexo lábio-maxilar curto, chegando às coxas posteriores em repouso, cerca de 1,4 vezes o comprimento do olho (625), igualando a largura da cabeça. Escapo mais longo que a distância alveolocelar, quase sete vezes seu diâmetro (200/D32: 150); flagelômeros tâo longos como 42: 25: 30 e o diâmetro do terceiro 
35. Tíbias médias com a franja ciliar bem desenvolvida e um pouco distanciada do ápice do coxim anterior, este estreito-cuneiforme $4 / 7$ do comprimento da área aveludada; tíbia posterior com o chanfro supracalcáreo simples sem tubérculos, franja póstero-distal amarela.

Exemplares vistos, além do tipo: 26 exemplares machos da Floresta da Tijuca e da Represa Rio Grande, Rio de Janeiro, I-1969, F. M. Oliveira leg.; 1 macho de Itatiaia, 700 m, J.F. Zikan leg., 22-II-1927, em flores de Stachytarpheta; 2 machos de Teresópolis, 900 m, C.A. Campos Seabra, 15-I-1958; numerosos machos do Estado de Espírito Santo: Santa Teresa, 675 m, ES, C.T. \& C. Elias leg. de abril de 1964 a novembro de 1967; 2 machos de Conceição da Barra, 10 m, C.T. e C. Elias leg. em 11-X-1967 e 25-IX-1969.

Na coleção Pe. J.S. Moure (Departamento de Zoologia, Universidade Federal do Paraná - DZUP) há alguns exemplares de Gran Guardia, Formosa, Argentina, XI-1952 (F. Walz) 1 fêmea; mais 1 fềmea do mesmo local coletada por J. Foerster e outra de Posadas, Misiones. De São Paulo: 1 fêmea de São Carlos, 1 fêmea de Piracicaba (XI-1965); de Santa Catarina: 1 fêmea de Caraguatá, Fritz Plaumann leg.; de Mato Grosso do Sul: Naviraí, 18-I-1977, M.A. Pereira leg.. Vários exemplares do Rio de Janeiro recebidos de Campos Seabra, e muitos do Espírito Santo: Santa Teresa, S. Mateus e Conceição da Barra, coletados por Claudionor Elias.

É constante em todos esses machos a presença da fímbria ciliar das tíbias médias ("brush") e a fimbria póstero-distal das posteriores de cor amarela. Outra constante é a larga estria superficialmente micro-reticulada na área supraclipeal entre o clípeo e o sulco frontal, raramente ocorrem exemplares com alguns pontos nessa estria.

Entre os numerosos exemplares de Santa Teresa há um com pontuação bastante densa na estria supraclipeal e as manchas escutais são um pouco mais acentuadas que nos exemplares típicos; em outro exemplar falta a fímbria ciliar das tíbias médias.

Formas aberrantes: Três machos de Santa Teresa, apresentam pequena mancha amarelo-pilosa na extremidade latero-distal do segundo tergo, e outras menores no terceiro e quarto tergos e invadindo por completo as porções látero-ventrais dos tergos 2-7 e formando faixas estreitadas para o meio nos E3-5. Em outro exemplar de Santa Teresa (1964) há apenas minúscula mancha amarelo-pilosa aos lados de T2 apicalmente. Um exemplar com as manchas amarelo-pilosas muito desenvolvidas foi coletado por C. Elias em Várzea Alegre, Espírito Santo, 10-III1967. Na Coleção Campos Seabra (MNRJ) há vários exemplares com essas manchas amarelo-pilosas. Talvez um possível cruzamento com E. mussitans ou com $E$. smaragdina, ambas muito comuns no Espírito Santo.

Na chave de KIMSEY (1982) com a fêmea chega-se ao dilema 18, indo para violascens (veja-se a descrição do tipo de Euplusia violascens [MOURE 1976: 284]). Com o macho chega-se ao dilema 79, indo para E. violacea (Blanchard, 1940), pela presença da fimbria ântero-tibial no segundo par de pernas). Espécie muito diferente pelo tamanho e colorido. Estudei muitos exemplares de violacea, provenientes de ninhos.

Na Amazônia ocorre ainda uma forma mais escura desta espécie que denomino. 


\section{Euplusia danielis fuscatra subsp.n.}

Macho. De tamanho igual ao anterior, talvez um pouco mais robusto. Comprimento total aproximado $19,5 \mathrm{~mm}$, da asa anterior $16,5 \mathrm{~mm}$; largura da cabeça $6,91 \mathrm{~mm}$, do T2 7,5 mm. Asas muito escuras; a pilosidade sobre as manchas escutais igualmente muito escura. As manchas escutais muito apagadas, de um verde-brônzeo muito escuro, dando a todo mesoscuto e escutelo uma tonalidade preta quase uniforme. A face de um verde-brônzeo muito escuro abaixo das carenas supralveolares, aos lados dos álveolos de um verde mais vivo. O colorido violáceo da forma típica, nesta fica praticamente preto com alguns reflexos muito escuros de um verde-brônzeo nos mesepisternos e alguns traços de violáceo nos últimos tergos.

As carenas laterais do clípeo fortes, subparalelas, pontuadas e unidas em cima em arco; a mediana fina e bem destacada nos dois terços inferiores; a estria supraclipeal muito densamente pontuada, os intervalos menores que os pontos, careniformes. A fimbria ciliar das tíbias médias formada por uma série de cerdas curtas de um castanho-claro ( $100 \mu$ chegando progressivamente a $500 \mu$ no ápice) e por trás outras retas (não curvadas para dentro como as da fimbria) desde a ponta do coxim anterior até próximo ao ápice da tíbia (de $400 \mu)$. Nas tíbias trazeiras a fímbria posterior formada por cerdas castanhas bastante numerosas porém relativamente curtas $(1000 \mu)$; as cerdinhas castanho-amareladas da face externa mais numerosas que em danielis, passando a pretas em cima, atrás e ao longo de todo bordo anterior; aquí mais longas. As tégulas quase pretas, com alguns reflexos violáceos a verde-brônzeos em certa luz; as asas muito escuras, com a venação e estigma pretos.

Fêmea: Comprimento total aproximado $18,35 \mathrm{~mm}$, asa anterior $14,5 \mathrm{~mm}$; largura da cabeça $6,83 \mathrm{~mm}$,do T2 $8,08 \mathrm{~mm}$. O complexo lábio-maxilar chegando às coxas posteriores. Inteiramente preta com reflexos violáceos fracos, em certa luz, nas paroculares superiores e nos tergos 2-6; no tergo basal os reflexos vão para um verde-garrafa muito escuro. A pilosidade inteiramente preta, mesmo as cerdas longas dos últimos tergos e esternos. Essas cerdas longas nas outras espécies do complexo auriceps são amarelas.

Holótipo e três parátipos machos, VI-1961, Santa Isabel do Morro, Ilha do Bananal (antigamente Goiás e agora incorporada ao estado de Tocantins), M. Alvarenga leg.. Três machos de VII-1955, uma macho de 15-IX-1955, Santarém, Pará, M.G. Silva leg. e três machos de VI-1952, Cachimbo, Pará, M. Alvarenga e F.M. Oliveira leg.. Todos na coleção Pe. J.S. Moure (DZUP).

\section{Euplusia raymoni (Schrottky, 1907) comb.n.}

Centris nigrita var. raymondi Schrottky, 1907: 65.

Eulaema nigrita; Kimsey \& Dressler, 1986: 234 (partim).

Tive a oportunidade de estudar o [holó]tipo de C. raymondi Schrottky, no Museu de Zoologia, Universidade de São Paulo, São Paulo. É uma Euplusia inteiramente preta, sem nenhum reflexo de cor metálica.

Fêmea relativamente grande: Comprimento aproximado $20,25 \mathrm{~mm}$, da asa anterior $14,95 \mathrm{~mm}$; largura da cabeça $6,72 \mathrm{~mm}$, do T2 $8,35 \mathrm{~mm}$. 
Inteiramente preta, sem área com reflexos de cor metálica. Tégulas pretas; asas escuras com a venação e estigma pretos; as pernas levemente acastanhadas.

Pilosidade preta, com algumas cerdas amarelas (até $1000 \mu$ ) nos dois últimos segmentos abdominais e alguns pelinhos amarelados nas paroculares e no clípeo. Bastante densa no tórax e no abdome, ocultando em grande parte a pontuação.

Pontuação da fronte relativamente fina (cerca de $60 \mu$ ), os intervalos pouco maiores que os pontos com pontinhos intercalados nos dois terços inferiores, mais estreitos e os pontos um pouco menores e mais densos em direção ao ocelo médio; carenas supralveolares (limitantes superiores da depressão alveolar) e as adocelares (aos lados e unidas acima do ocelo médio) relativamente lisas; uma área lisa nas paroculares ao lado dos alvéolos e maiores que o diâmetro dos mesmos, um pouco mais esparsa e maior (até $150 \mu$ ) abaixo dessas áreas; no clípeo um pouco mais fina, acima os intervalos reticulados junto a carena média, lisa, os pontos maiores e mais próximos entre si, os intervalos reticulados, para baixo maiores (nos cantos inferiores até $150 \mu$ ) e mais densos na extremidade inferior; atrás dos ocelos fina e densa deixando fraca carena média lisa atrás; áreas ocelorbitais largamente sem pontos e estes muito finos aos lados das fóveas adocelares; densos nas genas ficando mais esparsos junto as órbitas. Fina e densa no mesoscuto com alguns pontos maiores (ate $60 \mu$ ) intercalados no disco posterior e menos diversificada na porção anterior; igual porém mais densa no escutelo com os pontos maiores até $50 \mu$; mais uniforme nos mesepisternos. Densa e fina nos tergos, muito uniforme, fina e densa, na metade basal do T2.

Cabeça mais larga que longa (672:557), os olhos um pouco mais longos que duas vezes sua largura (450:200) e as genas de pefil um pouco mais estreitas; labro mais largo que longo, densamente pontuado, truncado e com carena média basal chegando até o meio; área malar linear. Clípeo pouco mais longo que sua distância ao ocelo médio (220:200), com forte carena média lisa, ligeiramente atenuada nas extremidades; distância interocelar duas vezes o diâmetro do ocelo médio e maior que a distância ocelorbital (90:70:D45). Antenas normais; o escapo (200) com alguns pêlos na base chegando a um diâmetro do mesmo). Complexo labio-maxilar longo, cerca de 3,4 vezes o comprimento do olho (1495), chegando em repouso até $\mathrm{o}$ ápice do abdome.

Um exemplar de Rancho Grande, 1100 m, Aragua, Venezuela, em 21-VIII1974, F. Fernando Y. e C.J. Rosales leg.. Recebida do Dr. Yepes quando em visita à Maracay em 1980 e comparada com o tipo no Museu de Zoologia da Universidade de São Paulo.

Com esse exemplar na chave de KIMSEY (1982) vai para $3 \rightarrow 7 \rightarrow 11 \rightarrow 12$, sem entrar bem pois T5-6 com cerdas em grande parte amarelentas, porém a cabeça e tórax pretos, sem reflexos de colorido metálico. Aproxima-se mais de nigrescens pelo colorido e pilosidade dos dois últimos segmentos abdominais, o complexo labio-maxilar até o ápice do abdome. Comparei-a com um exemplar de $E$. longipennis (Friese, 1925) colocada na sinonímia por KIMSEY (1982: 67).

As cerdas no vértice de E. longipennis chegam a $1600 \mu$ e em E. raymondi mais curtas, até $1200 \mu$, a carena clipeal mais fraca, a área malar distinta (20), o complexo labio-maxilar um pouco mais curto (995, olho 420). Além disso em certa luz com alguns reflexos azul-aço nas áreas paroculares próximas aos alvéolos; a 
pontuação do clípeo mais densa e os intervalos fortemente reticulados, a carena média menos saliente. Este exemplar de E. longipennis procede de Florencia, Caquetá, na Colômbia Amazônica.

Note-se que na chave para as "Centris" do Paraguay não ha referência ao colorido do abdome, que facilmente separaria $E$. nigrita da chamada var. raymondi. $\mathrm{Na}$ descrição de Schrottky é apenas destacado o comprimento da língua para separá-la de E. nigrita.
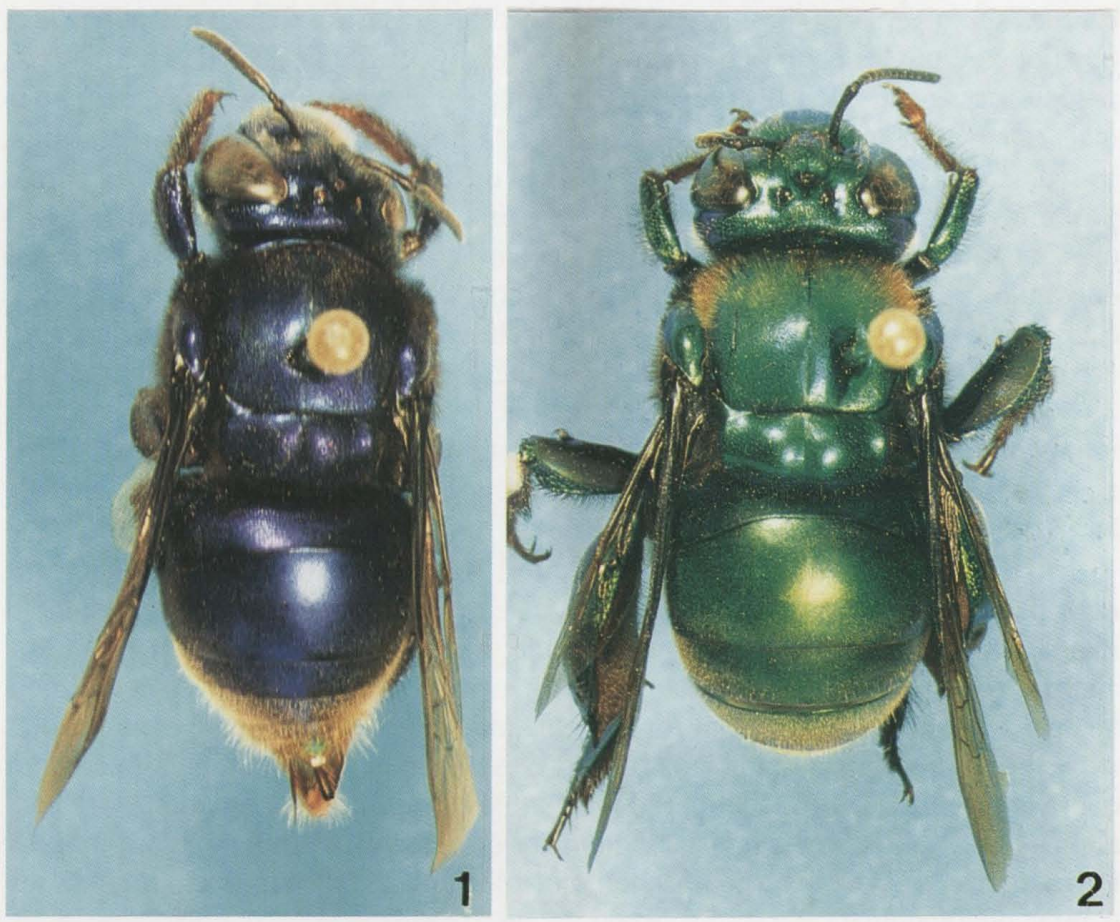

Figs 1-2. Euplusia fragocara. (1) Fêmea; (2) macho.

\section{Euplusia fragocara Kimsey, 1977 \\ Figs 1-2}

Euplusia fragocara Kimsey, 1977: 13.

Numeros exemplares de Ouro Preto d'Oeste, Rondônia, antes somente conhecida de Pachitea, Huánuco, Peru, confirmam a previsão de KIMSEY (1977) para o colorido das fêmeas, de um violáceo intenso como em $E$. violacea, e pilosidade parecida porém curta e preta, no T2 e T3 mais densa, aos lados de T3 e nos seguintes tergos e esternos de um amarelo muito claro. No clípeo apenas a carena média bastante forte e lisa, praticamente sem depressões aos lados, e continuada por estria lisa até o sulco frontal. A pontuação na face mais esparsa particularmente no escudo frontal com os intervalos maiores que os pontos. 
A fềmea coletada em Ariquemes, Rondônia, por C.G. Mielke leg., 7-X-1987, tem o comprimento aproximado de $19,2 \mathrm{~mm}$, asa anterior $13,35 \mathrm{~mm}$; largura da cabeça $6,35 \mathrm{~mm}$ e do T2 7,08 $\mathrm{mm}$. Comprimento do complexo lábio-maxilar 8,75 $\mathrm{mm}$, cerca de 2,15 o comprimento do olho, chegando em repouso até a base de E1.

Pelo tamanho lembra mais a $E$. caerulescens (Lepeletier, 1841), do México, porém nesta última a pontuação da face mais densa, a carena média do clípeo mais fraca, labro com três carenas, as laterais convergentes para baixo. Em E. fragocara há apenas uma carena média bastante forte, grossa e lisa nos dois quintos basais. Em um dos exemplares de E. caerulescens de Tehuitzingo, Puebla, México, o complexo lábio-maxilar chega em repouso até o ápice do E2, com 10,42 mm, ou 2,6 vezes o comprimento do olho, podendo ser colocada entre as Euplusia de "língua longa"!

Na chave de KIMSEY (1982), ao final do dilema onde consta caerulescens, substituir por 26.

Infelizmente não posso compará-la com E. simillima Moure \& Michener, 1965 , pois tenho apenas um macho da localidade típica. Nesse exemplar a pontuação da face é mais esparsa, particularmente no escudo frontal, as carenas clipeais muito obsoletas e as do labro fortes. O complexo lábio-maxilar mede 7,5 mm, o olho 4,15 $\mathrm{mm}$, ou 1,8 vezes mais longo.

Comparando a proporção entre o coxim anterior, a área aveludada posterior e a presença da fimbria ciliar dos machos dessas quatro espécies temos:

\begin{tabular}{lll}
\multicolumn{1}{c}{ coxim anterior/area aveludada } & \multicolumn{1}{c}{ fimbria ciliar } \\
violacea & $200 / 280=0,714$ & ligada ao coxim \\
fragocara & $200 / 320=0,625$ & separada do coxim \\
caerulescens & $120 / 280=0,428$ & ausente \\
simillima & $140 / 280=0,500$ & ausente
\end{tabular}

\section{Euplusia smaragdina (Perty, 1833)}

Centris smaragdina Perty, 1833: 150.

Euglossa smaragdina; Smith, 1854: 382, 12. - Smith, 1874: 445, 6. - Dalla Torre, 1896: 311. - Friese, 1899: 148. -Schrottky, 1902: 593, 15.

Euplusia samaragdina; Moure, 1944: 13. - Moure, 1960: 17.

Eufriesea surinamensis; Kimsey, 1982: 80. (partim Syn.). - Kimsey \& Dressler, 1986: 231. (partim Syn.).

Cometi erros na determinação desta espécie, sendo minhas referências a exemplares de $E$. smaragdina realmente a indivíduos de $E$. surinamensis, exceto no meu estudo de 1960, quando comparei com o tipo de Perty um exemplar de $E$. surinamensis, procedente da Floresta da Tijuca, Rio de Janeiro, em que anotei as diferenças entre o mesmo e o tipo. Naquele tempo ainda não atribuia ao comprimento do complexo labio-maxilar a importância que passei a dar-lhe desde meu trabalho (1976) de "Revisão das espécies de Euplusia descritos por Mocsáry" e que veio a ser usado como básico para as grandes divisões na monografia de KIMSEY (1982). O tipo foi por mim reestudado em Munich em 1986 e constatei ser um dos representantes de "língua curta" chegando esta até as coxas posteriores. 
Euplusia smaragdina foi descrita de Minas Gerais e posteriormente foi encontrada no Espírito Santo e se estende pela Mata Atlântica até o Litoral do Paraná, tendo sido coletado um exemplar por O. Mielke e Moure na Praia de Leste, ao Sul da Baia de Paranaguá.

\section{Euplusia faceta sp.n.}

Fêmea. De tamanho médio. Comprimento aproximado $15,8 \mathrm{~mm}$, da asa anterior $13,5 \mathrm{~mm}$; largura da cabeça $6,25 \mathrm{~mm}$ e do $\mathrm{T}-27,90 \mathrm{~mm}$.

Cabeça e tórax de um violáceo escuro, quase preto; com reflexos violáceos mais evidentes nas paroculares aos lados dos alvéolos antenais, pronoto, metade anterior do mesoscuto, tégulas, parte anterior dos mesepisternos; reflexos brônzeoescuros com um pouco de verde no escutelo, no primeiro tergo e metade basal do segundo em arco recurvo, nos lados do segundo e do terceiro ao quinto cúpreo a latão dourado com pequena mancha purpúrea no disco do terceiro, o sexto multicolorido (purpúreo, bronzeado e com reflexos verdes). As tégulas de um violáceo intenso; as asas bastante escuras com a venação e estigma negros.

Pilosidade preta na cabeça, tórax e nos dois primeiros tergos, posteriormente nos lados do segundo e em todos os tergos seguintes fulvo-amarelada, nos esternos um pouco mais pálida.

Pontuação fina (40-30 $\mu$ ) e muito densa na área frontal (os pontos mais finos em cima), na supraclipeal e aos lados da estria mediana lisa; um pouco mais grossa e inclinada no clípeo, mais grossa nas paroculares sem deixar área lisa látero-alveolar; no labro bastante densa com pontos grossos e finos misturados $(80-40-20 \mu)$; nas genas densa e uniforme. Densa e fina no mesoscuto, no terço posterior duas áreas com pontos grandes mais esparsos e pequenos intercalados; no escutelo muito densa, claramente de dois tamanhos; nos mesepisternos muito densa os pontos uniformes e os intervalos careniformes. Nos tergos fina e densa, no primeiro tergo para a base mais grossa e mais esparsa; no segundo muito densa e uniforme, nos últimos um pouco mais grossa que no segundo.

Cabeça um pouco mais larga que longa (625:440); olho pouco mais de duas vezes sua largura e as genas apenas a metade da largura do olho (420:200:100), área malar linear (10); órbitas mais afastadas entre si em baixo que em cima, a interorbital máxima mais curta que o comprimento do olho (280:360:320). Clípeo 1,55 vezes mais largo que longo, seu comprimento igual à distância clipeocelar (280: 180: 180); a carena média fina e lisa, abreviada nas extremidades, continuada por estria lisa estreita na supraclipeal até abraçar o sulco frontal; carenas supralveolares bastante lisas a inferior a área frontal em arco e as adocelares um pouco pontuadas; a distância interalveolar quase três diâmetros de alvéolo e 1,45 vezes a alveolorbital (116:80: D40). Complexo labro-maxilar curto chegando às coxas posteriores em repouso, 1,6 vezes o comprimento do olho (670:420). Labro 1,6 vezes mais largo que longo (160:100), truncado apicalmente, com carena basal fina, tão longa como o diâmetro do alvéolo e uma fraquíssima a cada lado convergentes para baixo, praticamente tão distantes do meio como dos lados. Escapo quase seis vezes seu diâmetro, mais longo que a distância alveolocelar (190:30:160); o primeiro flagelômero três vezes o 
comprimento do terceiro, este um pouco mais longo que o segundo, claramente mais curto que seu diâmetro (90:26:30:D36). Escutelo um pouco mais longo que duas vezes seu comprimento (440:212), com o bordo posterior fracamente recurvo e levemente deprimido ao longo do meio.

Holótipo macho de 22-XII-1979, Mucujé, Bahia, Brasil, alt. 984 m, próximo ao Parque Nacional de Diamantina. F. P. Benton col. Em flores de Cuphea. Depositado na coleção Pe. J.S. Moure (DZUP).

Na chave de KIMSEY (1982), chega-se imperfeitamente à E. violascens (Mocsáry, 1898) baseada em dois exemplares pertencentes a espécies diferentes, separados por MOURE (1976), reservando o nome E. violascens para o exemplar de Songo na Bolívia (Encosta Andina) e reconhecendo o exemplar de Blumenau, Santa Catarina, como a fêmea de $E$. auriceps (Friese, 1899) de acordo com exemplares retirados de ninhos estudados por R. Zucchi e que situam esta espécie na Mata Atlântica, onde tem várias espécies correlacionadas.

Em E. violascens o colorido é fortemente violáceo-púrpura intenso com alguns reflexos verde-azul-escuros nos tergos. Na minha coleção há machos e fêmeas do Departamento de Cochabamba, Bolívia. A cabeça tem a largura de 6,55 $\mathrm{mm}$.

Euplusia auriceps é um pouco maior e mais robusta. A cabeça da fêmea mede 6,45-6,9 mm. Tem uma distribuição ampla, desde o Norte da Argentina (Jujuy, Formosa e Misiones), Paraguai e Sul (Rio Grande do Sul, Santa Catarina, Paraná), Centroeste (Mato Grosso do Sul, Goiás) e Sudeste do Brasil (São Paulo, Minas Gerais, Rio de Janeiro, Espírito Santo). As fêmeas do sudoeste da distribuição (Bacia do Paraguai) foram descritas como Centris violascens por SCHROTTKY (1907).

De um modo geral os machos da verdadeira $E$. auriceps tem um colorido mais modesto que os exemplares provenientes do litoral. Na metade inferior da face predomina o verde-garrafa com alguns reflexos para o verde-claro-dourado; no vértice e genas, o violáceo. As manchas escutais de um verde menos vistoso e a pilosidade de cor castanha; no restante do tórax, metade posterior das tégulas e em todos os tergos de um violáceo escuro. As tíbias posteriores vermelho-castanho-escuras, lembrando machos de E. smaragdina (Perty, 1833), E. rugosa (Friese, 1899) e E. nigrohirta (Friese, 1899). Há alguns machos com tíbias mais escuras nesta e nas espécies acima citadas. As carenas clipeais em cima, mais pontuadas, juntam-se em parábola e para baixo são um pouco convergentes e mais lisas; a carena média muito obsoleta mais distinta no quinto apical; no labro a carena média forte e aguda nos $7 / 9$ basais, as laterais fortes, salientes e agudas, convergentes para baixo nos $2 / 3$ basais e subparalelas no terço distal; as mandíbulas bidentadas de contorno externo em arco regular. E. auriceps $\mathrm{e} E$. danielis ocorrem juntos desde o Norte da Argentina e do Paraguay até Espírito Santo, no Brasil.

A forma mais vistosa de E. auriceps tem as mancha prescutais de um verde vivo cobertas por pilosidade esbranquiçada e o abdome predominantemente esverdeado; ocorre ao longo do litoral da Mata Atlântica, desde Santa Catarina até Espírito Santo, entrando bastante para o interior em São Paulo, e sudoeste de Minas Gerais, sendo comum no Triângulo Mineiro. 


\section{Euplusia nordestina sp.n.}

Do grupo auriceps, lembrando pela pilosidade densa e aveludada do tórax a E. danielis (Schrottky), porém mais preta, os reflexos metálicos muito reduzidos.

Fêmea de porte médio. Comprimento total aproximado $18,30 \mathrm{~mm}$, da asa anterior $14,15 \mathrm{~mm}$; largura da cabeça $6,58 \mathrm{~mm}$, do T2 7,5 $\mathrm{mm}$.

Predominantemente preta. Com reflexos azul-escuros no clípeo, violáceos nas paroculares, nas genas ao longo das órbitas externas; negro-violáceos, em certa luz, em T3-5 e verde-brônzeos no terço apical de T6. As pernas negro-avermelhadas particularmente a face externa das tíbias posteriores e os fêmures de todos os pares; nas tíbias dos dois primeiros pares com reflexos viláceos fracos. As tégulas com os $2 / 5$ anteriores violáceos, pretas atrás; asas castanho-escuras, principalmente a célula radial; a parte livre apical um pouco mais clara, venação e estigma pretos.

Pilosidade preta em todo corpo menos nos lados do clípeo, nas paroculares inferiores e algumas cerdas no vértice de um amarelo-pálido bem visível de perfil; as cerdas dos últimos tergos e esternos pretas. Muito densa -mente aveludada no tórax cobrindo a pontuação; bastante densa nos tergos, estes com uma margem estreita glabra e desbotada. As cerda corbiculares da margem posterior das tíbias muito curtas $(200 \mu)$ e bastante grossas, espiniformes. Cerdas no disco do segundo tergo curtas $(200 \mu)$ e as mais longas do último tergo cerca de $800 \mu$.

Pontuação densa no escudo frontal, os intervalos careniformes e os pontos um pouco confusamente de dois tamanhos $(50 \mu$ e $20 \mu)$; nas paroculares grossa e muito densa, deixando larga área lisa ao lado dos alvéolos ocupando cerca da metade da área alveolorbital; as carenas supralveolares e adocelares quase inteiramente lisas; no clípeo mais grossa (até $80 \mu$ ) parcialmente inclinada, a carena média micro-reticulada continuada na supraclipeal por uma estria lisa até o sulco frontal, aos lados da supraclipeal muito densa. No labro densa, os intervalos careniformes e alguns micropontos intercalados. No mesoscuto e escutelo coberta pela pilosidade, podendo ver-se no disco posterior do mesoscuto pontos de dois tamanhos $(40 \mathrm{e} 20 \mu)$, os maiores mais esparsos; nos mesepisternos bastante maiores e outros menores intercalados muito densamente (desde $100 \mu$ até $20 \mu$ ). No segundo tergo muito densa e uniforme (pontos com sensilas um pouco maiores e mais brilhantes), nos seguintes ficando um pouco mais forte.

Cabeça mais larga que longa (658:540); olhos grandes, as genas cerca da metade da sua largura (460:220:105); malar linear (5); órbitas mais afastadas em baixo e a distância máxima menor que o comprimento do olho (280:360:320). O clípeo 1,5 vezes mais largo que longo, seu comprimento um pouco maior que a distância ao ocelo médio (300:200:190); carena média bem desenvolvida, toda tesselada, tão larga como meio diâmetro do ocelo médio, as laterais fracas subparalelas, pontuadas, encurtadas em cima e em baixo; uma estria larga na supraclipeal abraçando o sulco frontal. Distância interalveolar quase dois diâmetros de alvéolo, a alveolorbital 5/7 (110;80:D60); áreas lisas tão largas como meia distância alveolor-bital; carenas supralveolares e frontocelares bem marcadas, parcialmente lisas. Labro pouco abaulado, 1,6 vezes mais largo que longo (175:105), o ápice em arco procurvo muito rebaixado, a carena média em estreito triângulo acuminado chegan- 
do quase até o ápice em carena linear; mandíbulas tridentadas; complexo lábio-maxilar curto chegando às coxas médias, uma vez e meia o comprimento do olho $(6,65$ $\mathrm{mm}$ ). Escapo sete vezes seu diâmetro, claramente mais longo que a distância alveolocelar (220:165); flagelômero basal pouco mais longo que o diâmetro do terceiro, este mais curto que o diâmetro porém mais longo que o segundo (40:25:30: D36). Escutelo pouco mais largo que duas vezes seu comprimento, levemente abaulado, truncado com os cantos arredondados, sem depressão média.

Holótipo fêmea, 14-V-1955, de Santa Luzia, 300m, Paraiba, no sertão Paraibano, L. Portela leg. Depositado na Coleção Pe. J.S. Moure (DZUP).

Na chave de KIMSEY (1982) vai a E. violascens. Parece-se com E. velutina, porém mais escura, com reflexos de negro-violáceo, sem cerdas amarelas nos últimos segmentos abdominais. Lembra também fuscatra, porém nesta sempre há mais reflexos esverdeado-violáceos, a carena labral mais curta, maior e mais robusta. Comparando-a com espécies andinas pretas chega-se a E. buchwaldi (Friese, 1923) que difere pela pontuação mais esparsa na face, mesonoto e tergos e particularmente pelas áreas lisas no disco posterior do mesoscuto com intervalos entre os pontos de 5-7dp, pela pilosidade menos densa no tórax e abdômen e pelas cerdas amarelas longas nos dois últimos segmentos abdominais. Os reflexos azul-violáceos muito mais acentuados nas áreas paroculares de buchwaldi, porém com o abdômen e as pernas inteiramente pretos e as cerdas corbiculares finas e longas até $700 \mu$.

E. buchwaldi foi colocada por KIMSEY (1982), na sinonimia de E. venezolana (Schrottky, 1913).

\section{Euplusia velutina sp.n.}

Trata-se de uma Euplusia do complexo em estudo, mas do extremo norte de sua distribuição (Mérida, Venezuela).

Está na minha coleção há quatro anos com este nome, esperando por mais exemplares e algum macho da região.

Quando KIMSEY (1977) descreveu E. boharti, pensei ser a presente espécie a fêmea. A espécie de Kimsey vem de outra região dos Andes Venezolanos, Rancho Grande, Aragua. Não tenho exemplares de boharti e encontrei várias dificuldades para incluí-lo no complexo auriceps, embora seu colorido possa ser sugestivo para essa afinidade. No grupo auriceps, o complexo labio-maxilar atinge em repouso as coxas posteriores, ficando ao redor 1,6 vezes o comprimento do olho. Em E. boharti aparentemente é mais curto ( $5 \mathrm{~mm}$, cerca de um terço do comprimento do corpo), enquanto que em auriceps as prop/orções são diferentes: complexo lábio-maxilar $7,5 \mathrm{~mm}$, comprimento do corpo $16,7 \mathrm{~mm}$ e comprimento do olho $4,58 \mathrm{~mm}$, ficando ao redor dos quatro nonos.

Neste complexo, nada que se compare com a faixa de pilosidade amarela no bordo anterior das tíbias posteriores, o coxim anterior um terço da área aveludada e principalmente a presença de uma única carena média no clípeo. Também as duas carenas do labro "meeting medially" no dizer de Kimsey, torna qualquer comparação impossível.

Fêmea de porte médio: Comprimento total aproximado $18,0 \mathrm{~mm}$, da asa anterior $14,0 \mathrm{~mm}$; largura da cabeça $6,45 \mathrm{~mm}$ e do $\mathrm{T} 27,9 \mathrm{~mm}$. 
Predominantemente violáceo-escura, um pouco para o magenta; labro e base das mandíbulas verde-garrafa escuro e a carena média do clípeo igual, porém brilhante; vértice brônzeo-escuro; escapo e grande parte dos fêmures castanho-avermelhados; reflexos azulados no propódeo; no primeiro tergo o violáceo mais acentuado e verde-garrafa dourado no sexto tergo. Tégulas violáceo-eşcuras; asas escuras, particularmente a célula radial; venação e estigma pretos. Pilosidade toda preta fora alguns pelinhos amarelo-pálidos em parte nas paroculares inferiores, nas depressões alveolares e no escapo e algumas cerdas longas nos lados dos dois últimos tergos.

Pontuação da área frontal de dois tamanhos, predominando os pontos grossos $(50 \mu)$ na parte inferior; no clípeo um pouco inclinada e mais grossa (até $80 \mu$ ) e nas depressões aos lados da carena média um pouco mais esparsa; na supraclipeal densa e um pouco mais fina, deixando uma estria lisa estreita ligando a carena média lisa do clípeo ao sulco frontal; carenas supralveolares e adocelares com alguns pontos grossos, as adocelares mais fortes; nas áreas paroculares inferiores um pouco mais fina que no clípeo e nas superiores um pouco mais esparsa sem formar área lisa látero-alveolar distinta; no vértice densa, porém nas áreas ocelorbitais com uns poucos pontos grossos $(40 \mu)$ intercalados por muitos ponto finos; nas genas mais grossos $(60 \mu)$ e uniformes. No mesoscuto e escutelo densa coberta pela pilosidade, no disco posterior do mesoscuto e no escutelo de dois tamanhos $(30 \mu$ e $50 \mu)$; nos tergos fina, densa e uniforme.

Cabeça mais larga que longa (665:575); olhos grandes um pouco mais longos que duas vezes sua largura e as genas cerca da metade (440:210:100); órbitas mais próximas em cima e a maior distância interobital menor que o comprimento do olho (290:370:320); área malar muito estreita (5). Clípeo pouco mais largo que 1,5 vezes seu comprimento e este menor que sua distância ao ocelo médio (312:200:220); a carena média bem definida, relativamente fina e lisa, completa, a área aos lados da mesma deprimida, com as depressões limitadas por carenas obsoletas, muito fracas; uma listra lisa fina continuando a carena clipeal até o sulco frontal; carenas supralveolares moderadas as frontocelares mais fortes; uma fina listra lisa no vértice. Labro quase 1,7 vezes mais largo que longo, truncado apicalmente com os cantos arredondados e uma carena curta média muito fraca; complexo lábio-maxilar curto, em repouso chegando até as coxas posteriores cerca de 1,7 vezes o comprimento do olho. Escapo mais longo que a distância alveolocelar (210/30:170); os três primeiros flagelômeros como 45:30:30:D39. Escutelo 1,85 vezes mais largo que longo, truncado com os cantos largamente arredondados, um pouco abaulado e a depressão média praticamente nula.

Holótipo fêmea, XI-1950, Mérida, Venezuela, recebida do Dr. Fernando Yepes. Na coleção Pe. J.S. Moure (DZUP).

Pela chave de KIMSEY (1982) vai ao dilema $19-E$. violascens - a que atribui sentido muito amplo.

Euplusia violacea (Blanchard, 1840) tem a pilosidade muito mais esparsa deixando ver perfeitamente o tegumento em todo corpo, é menor e o violáaceo mais vivo, a pilosidade baixa dos tergos esbranquiçada e as cerdas pretas longas (até 
$800 \mu$ ), a pontuação dos tergos um pouco mais grossa (quase $40 \mu$ e os pelinhos $150 \mu$ ), os intervalos lisos ligeiramente maiores que os pontos. $\mathrm{O}$ escutelo claramente deprimido ao longo do meio.

Em E. velutina como em E. auriceps os pelinhos dos tergos um pouco mais longos (200-250 $\mu$ ), muito densos, cobrindo o tegumento. As cerdas longas dos últimos tergos pretas e brancas em violacea, amarelas em auriceps, pretos e amarelos em velutina.

Em $E$. violascens a pilosidade nas fêmeas é toda preta, mais densa que em $E$. violacea, porém menos que em $E$. velutina e $E$. auriceps, deixando ver o tegumento fortemente violáceo com alguns reflexos azuis fracos em determinada luz, como nas espécies do grupo caerulescens (E. violacea, E. caerulescens, E. simillima e $E$. fragocara). Neste último grupo o dicroismo entre machos e fêmeas é muito acentuado (um pouco menos em $E$. simillima) enquanto que no grupo $E$. violascens que inclui também $E$. chalybaea (Friese, 1923) machos e fêmeas são fundamentalmente homócromos. Ainda para separar as fêmeas de $E$. violascens $e$ E. chalybaea dos grupos acima citados basta reparar no clípeo tricarenado. $E$. violacens é simpátrica com $E$. chalybaea no sul dos Andes Bolivianos, porém esta última é menor (cabeça $5,58 \mathrm{~mm}$, asa $13,7 \mathrm{~mm}$, contra $6,55 \mathrm{~mm}$ e $15,5 \mathrm{~mm}$ em violascens) e avança profundamente na Argentina, chegando a Sierra de Córdoba, exemplares enviados por M. Vianna.

Como vem sendo repetido em KIMSEY \& DRESSLER (1986: 231) que não se sabe onde está o típo ("repository unknown") de E. vidua Moure, 1976, chamo a atenção para o fato que isto consta claramente no início do meu trabalho de 1976, p. 264: "All these specimens belong to the National Hungarian Museum in Budapest", e ao referir-me ao exemplar descrito (p. 277) digo claramente que este é o mesmo considerado por Friese como fêmea de dentilabris e dou notícia de todas as etiquetas do tipo de Budapest! Confirmo assim que E. xantha Kimsey, 1977, deve passar a sinonímia de $E$. vidua Moure, 1976, que não mais poderá ser considerada como "viúva" ainda que pelo ICZN este nome deva permanecer!

Aproveito a oportunidade para chamar a atenção para a correta designação de Euplusia brasilianorum, como grafado por Friese em sua monografia (1899:147), e não brasilanorum (KIMSEY 1982: 33, 37; KIMSEY \& DRESSLER 1986: 230).

\section{REFERÊNCIAS BIBLIOGRÁFICAS}

Dalla Torre, C.G. DE. 1896. Catalogus Hymenopterorum hucusque descriptorum systematicus et synonymicus 10. Lipsiae, G. Eugelmian, p.1-642.

FrIESE, H. 1899. Monographie der Bienengattung Euglossa. Termész. Füzetek 22: 142-157.

KIMSEY, L.S. 1977. New species of bees in the genera Euplusia and Eufriesea. (Hymenoptera: Apidae, Euglossini). Pan-Pacific Ent. 53: 8-18.

1982 Systematics of Bees of the Genus Eufriesea (Hymenoptera, Apidae).

Univ. Calif. Publ. Ent. 95: 1-125. 
KIMSEY, L.S. \& R.L. Dressler. 1986. Synonymic Species List of Euglossini. Pan-Pacific Entomologist 62 (3): 229-236.

MourE, J.S. 1944. Apoidea da coleção do Conde Amadeu A. Barbielini (Hym., Apoidea). Rev. Ent., Rio de Janeiro, 15 (1-2): 1-18.

1960. Notas sobre os tipos de abelhas do Brasil descritas por Perty em 1833 (Hymenoptera - Apoidea). Bol. Univ. do Paraná, Zool., Curitiba, 6: 1-23. 1976. Notas sobre os exemplares tipos de Euplusia descritos por Mocsáry (Hymenoptera: Apidae). Studia Ent. 19: 263-314.

SCHROTTKy, C. 1902. Ensaio sobre as abelhas solitárias do Brasil. Rev. Mus. Paulista, São Paulo, 5: 330-613. 1907. Contribución al conocimiento de los himenópteros del Paraguay. III. An. Cien. Paraguayos 7 (1): 1-78.

SMITH, F. 1874. A revision of the genera Epicharis, Centris, Eulaema and Euglossa, belonging to the family Apidae, Section Corbiculipedes. Ann. Mag. Nat. Hist. (4) 13: 440-446.

Recebido em 06.III.1999; aceito em 22.VI.1999. 